\title{
Correction to: Area-restricted search in Magellanic Woodpeckers: importance of tree senescence, forest composition and open habitats
}

\author{
Pablo M. Vergara ${ }^{1}$ (D) Francisca Maron-Perez ${ }^{2} \cdot$ Diego Caro $^{3} \cdot$ Gerardo E. Soto ${ }^{4} \cdot$ Javier A. Simonetti ${ }^{2}$
}

Published online: 17 April 2021

(c) Deutsche Ornithologen-Gesellschaft e.V. 2021

Correction to: Journal of Ornithology

https://doi.org/10.1007/s10336-021-01878-w

In the original publication of the article, the affiliation of the author "Javier A. Simonetti" was numbered 1 instead of 2. The correct affiliation is "Facultad de Ciencias, Universidad de Chile, Santiago, Chile".

The statement "Konzentrierte Nahrungssuche bei Magellanspechten: Die Bedeutung von Baumalter, Waldzusammensetzung und Ofenhabitaten" which was inadvertently introduced in the second paragraph of the Introduction section. It has been removed and corrected in the original article.
The original article has been updated with the corrections.

Publisher's Note Springer Nature remains neutral with regard to jurisdictional claims in published maps and institutional affiliations.

The original article can be found online at https://doi.org/10.1007/ s10336-021-01878-w.

\section{Pablo M. Vergara}

pablo.vergara@usach.cl

1 Universidad de Santiago de Chile (USACH), Facultad Tecnológica, Departamento de Gestión Agraria, Santiago, Chile

2 Facultad de Ciencias, Universidad de Chile, Santiago, Chile

3 Departamento de Ingeniería Informática, Universidad de Santiago, Santiago, Chile

4 Cornell Lab of Ornithology and Department of Natural Resources, Cornell University, Ithaca, USA 